\title{
Implementing Practice Changes in Family Medicine to Enhance Care and Prevent Disease Progression
}

\author{
Marjorie A. Bowman, MD, MPA, Dean A. Seebusen, MD, MPH, and \\ Anne Victoria Neale, PhD, MPH
}

This issue epitomizes family medicine with a heavy emphasis on research to prevent illness and illness progression. Which patients will experience significant symptomatic knee osteoarthritis? Do the elderly use retail clinics, and what is the impact on care for chronic conditions? Does capitation payment enhance or decrease same-day access? How do primary care practices risk stratify to provide integrated care? Can risk screening and on-site providers enhance psychiatric care? What screening questions should we ask adolescents, to identify problematic drug use? A report on a practice intervention to improve opioid prescribing practices, and another on the significant level of depression in many patients taking opioid medications. Which works better for smoking cessation-e-cigarettes or nicotine gum? Reminders about teratogenic drugs and those that cause hyperpigmentation. Interdisciplinary care with pharmacists in the office does not help just the patients. We have several articles on diabetes-early diagnosis, and consideration of screening for prediabetes as a quality standard—with added commentaries about this possibility. (J Am Board Fam Med 2019;32:451-453.)

\section{Interdisciplinary, Team Care}

Interdisciplinary care, that is, shared care with different clinical disciplines, can enhance care. The assistance of trained pharmacists can be quite useful in the office, providing several benefits for the primary care physicians, plus the patients. ${ }^{1}$ Perhaps having pharmacists in the office would help prevent the issue detected by Panchal et $\mathrm{al}^{2}{ }^{2}$ that is, prescribing medications that are contraindicated in pregnancy to women of childbearing age but without documenting current contraception use. Certainly, this is a reminder to avoid known or potentially teratogenic prescriptions for women who are at risk of pregnancy. Further, Kroll et $\mathrm{al}^{3}$ found that patients, often the underserved, benefit from a psychiatric walk-in clinic in an integrated primary care practice. The Agency for Health care Research \& Quality funded the multi-state intervention research reported by Hall et al. ${ }^{4}$ This study used practice support to improve cardiovascular care through patient-team partnership, and the authors report on patient-team partnership scores.

Conflict of interest: The authors are editors of the JABFM.

\section{Diabetes and Sugar}

Most family physicians in a single office setting thought that screening for prediabetes was important. ${ }^{5}$ See also the commentary from Dr. Mainous. ${ }^{6}$ Venkataramani et $\mathrm{al}^{7}$ remind us that if the parents are eligible for the National Diabetes Prevention Program, their children would often benefit as well, suggesting a need for family-oriented approaches. Pinon et $\mathrm{al}^{8}$ provide data from a rural clinic finding a higher rate of sugar-sweetened beverage consumption than the national average. They also note that the amount of sugar-sweetened beverage intake did not differ by body mass index (BMI), highlighting that these beverages are only 1 factor in the growing obesity trend.

\section{Patient Priorities for Care}

Patient-defined psychosocial previsit priorities are less likely to be addressed in primary care visits than patient-defined medical priorities, ${ }^{9}$ probably for multiple reasons. One patient priority-housing-was explored by Martin et al. ${ }^{10}$ Specifically, adults with housing insecurity forego health care, and often lack a usual source of care. This study was based on the $>10 \%$ of adults who responded positively to 1 question on worry about paying rent or 
mortgage over the past year. However, Betz et $\mathrm{al}^{11}$ report that driving safety does not seem to be a priority for aging adults, their physicians, or their families.

Although uncommon, elderly people do visit retail clinics, ${ }^{12}$ highlighting a priority for convenience. Unfortunately, obtaining care in retail clinics is associated with reduced continuity of care, even for serious illnesses (such as congestive heart failure), which are known to benefit from care continuity. Greater availability of same-day access could help to improve continuity. In a comparison of alternative payment methodologies, Heintzman et $\mathrm{al}^{13}$ found that the clinics with newly initiated capitation for care of Medicaid primary care patients had a greater increase in same-day visits compared with comparison offices. Several other hypothesized differences did not materialize, limiting the evidence for the benefits of alternative payment methodologies.

\section{Substance Use}

Four articles address substance use. Lin et $\mathrm{al}^{14}$ used the data from the National Ambulatory Medical Care Survey to identify higher rates of narcotic prescriptions in patients with depression; this paindepression association needs further exploration to help us know how to treat patients with pain and depression. Chavez et $\mathrm{al}^{15}$ undertook analyses of data from a national household survey to identify questions to screen for tobacco dependence and drug use disorders in adolescents, similar to those in wide use for adults. The article provides validation of questions for adolescents, making the results quite useful! And, is it possible to improve opioid prescribing practices through use of a multicomponent educational intervention? Arizmendez et $\mathrm{al}^{16}$ report a study of 2 clinics with a majority of patients seen by residents. Thankfully, the article includes specific handouts that can be used for provider training. In an article from Korean family physicians, Lee et $\mathrm{al}^{17}$ undertook a randomized trial of e-cigarettes compared with nicotine gum to help people stop smoking. These data add another choice to the options for patients.

\section{Additional Topics}

From the Netherlands, Landsmeer et $\mathrm{al}^{18}$ attempt to determine who should receive additional interventions to prevent symptomatic knee osteoarthri- tis. In addition to widely known risk factors-age and BMI-the authors provide more specificity to symptoms (pain with climbing stairs and morning stiffness) and other history (postmenopausal and history of heavy work) that should encourage earlier intervention.

Primary care risk stratification may improve health outcomes and help practices initiate appropriate interventions. Wagner et $\mathrm{al}^{19}$ report on the experiences of 15 primary care practices in different geographic locations. Some common methods were identified and reported.

Farford et $\mathrm{al}^{20}$ used methods previously shown to prevent readmissions, and added some. The authors found that their attempts did not decrease readmissions further, but were sufficiently worthwhile to continue using. And, finally, Giménez García and Carrasco Molina ${ }^{21}$ provide a helpful overview of the very large number of drugs that can cause hyperpigmentation, with accompanying pictures to help identify common types.

To see this article online, please go to: http://jabfm.org/content/ 32/4/451.full.

\section{References}

1. Funk KA, Pestka DL, Roth McClurg MT, Carroll JK, Sorensen TD. Primary care providers believe that comprehensive medication management improves their work-life. J Am Board Fam Med 2019; 32:462-73.

2. Panchal BD, Cash R, Moreno C, et al. High risk medication prescriptions in primary care for women without documented contraception. J Am Board Fam Med 2019;32:474-80.

3. Kroll DS, Latham C, Mahal J, et al. A successful walk-in psychiatric model for integrated care. J Am Board Fam Med 2019;32:481-89.

4. Hall TL, Knierim KE, Nease DE Jr, et al. Primary care practices' implementation of patient-team partnership: Findings from EvidenceNOW Southwest. J Am Board Fam Med 2019;32:490-504.

5. Keck JW, Thomas AR, Hieronymus L, Roper KL. Prediabetes knowledge, attitudes, and practices at an academic family medicine practice. J Am Board Fam Med 2019;32:505-12.

6. Mainous AG 3rd, Schatz DA. Is it time to prioritize diabetes prevention in practice? J Am Board Fam Med 2019;32:457-59.

7. Venkataramani M, Cheng TL, Yeh HC, Maruthur NM. Lifestyle intervention programs for adults at high-risk for type 2 diabetes: A platform to reach high-risk children? J Am Board Fam Med 2019;32: 596-600. 
8. Pinon L, Khandalavala B, Geske J. Sugar-sweetened beverage intake in a rural family medicine clinic. J Am Board Fam Med 2019;32:601-06.

9. Santo EC, Vo MT, Uratsu CS, Grant RW. Patientdefined visit priorities in primary care: Psychosocial versus medically-related concerns. J Am Board Fam Med 2019;32:513-20.

10. Martin P, Liaw W, Bazemore A, Jetty A, Petterson $\mathrm{S}$, Kushel M. Adults with housing insecurity have worse access to primary and preventive care. J Am Board Fam Med 2019;32:521-30.

11. Betz ME, Villavicencio L, Kandasamy D, et al. Physician and family discussions about driving safety: Findings from the LongROAD study. J Am Board Fam Med 2019;32:607-13.

12. Ogechi Abara N, Huang N, Raji MA, Kuo Y-F. Effect of retail clinic use on continuity of care among medicare beneficiaries. J Am Board Fam Med 2019; 32:531-38.

13. Heintzman J, Cottrell E, Angier H, et al. Impact of alternative payment methodology on primary care visits and scheduling. J Am Board Fam Med 2019; 32:539-49.

14. Lin SX, Patel K, Younge RG. Opioid medications prescribing and the pain-depression dyad in primary care: Analysis of 2014-2015 National Ambulatory
Medical Care Survey (NAMCS) data. J Am Board Fam Med 2019;32:614-18.

15. Chavez LJ, Bradley KA, Lapham GT, Wickizer TM, Chisolm DJ. Identifying problematic substance use in a national sample of adolescents using frequency questions. J Am Board Fam Med 2019;32:550-58.

16. Arizmendez NP, Kotovicz F, Kram JJF, Baumgardner DJ. Multimodal local opioid prescribing intervention outcomes in chronic noncancer pain management. J Am Board Fam Med 2019;32:559-66.

17. Lee S-H, Ahn S-H, Cheong Y-S. Effect of electronic cigarettes on smoking reduction and cessation in Korean male smokers: a randomized controlled study. J Am Board Fam Med 2019;32:567-74.

18. Landsmeer MLA, Runhaar J, van Middelkoop M, et al. Predicting knee pain and knee osteoarthritis among overweight women. J Am Board Fam Med 2019;32:575-84.

19. Wagner J, Hall JD, Ross RL, et al. Implementing risk stratification in primary care: Challenges and strategies. J Am Board Fam Med 2019;32:585-95.

20. Farford B, Pantin SA, Presutti J, Ball CS. Evaluation of a family medicine transitional care service line. J Am Board Fam Med 2019;32:619-27.

21. Giménez García RM, Carrasco Molina S. Druginduced hyperpigmentation: review and case series. J Am Board Fam Med 2019;32:628-38. 